\title{
Comparison of World Health Organization and Asia-Pacific body mass index classifications in COPD patients
}

This article was published in the following Dove Press journal:

International Journal of COPD

21 August 2017

Number of times this article has been viewed

Jeong Uk Lim,' Jae Ha Lee, ${ }^{2}$ Ju Sang Kim, ${ }^{3}$ Yong II Hwang, Tae-Hyung Kim, ${ }^{5}$ Seong Yong Lim, ${ }^{6}$ Kwang $\mathrm{Ha} \mathrm{Yoo,}{ }^{7}$ Ki-Suck Jung, ${ }^{4}$ Young Kyoon Kim, ${ }^{8}$ Chin Kook Rhee ${ }^{8}$

'Division of Pulmonary, Critical Care and Sleep Medicine, Department of Internal Medicine, St Paul's Hospital, College of Medicine, The Catholic University of Korea, ${ }^{2}$ Division of Pulmonology, Department of Internal Medicine, Inje University College of Medicine, Haeundae Paik Hospital, Busan, ${ }^{3}$ Division of Pulmonary Medicine, Department of Internal Medicine, Incheon St Mary's Hospital, College of Medicine, The Catholic University of Korea, Incheon, ${ }^{4}$ Division of Pulmonary, Allergy and Critical Care Medicine, Department of Internal Medicine, Hallym University Sacred Heart Hospital, Hallym University College of Medicine, Anyang, ${ }^{5}$ Division of Pulmonary and Critical Care Medicine, Hanyang University Guri Hospital, Hanyang University College of Medicine, Guri, ${ }^{6}$ Division of Pulmonary and Critical Care Medicine, Department of Medicine, Kangbuk Samsung Hospital, Sungkyunkwan University School of Medicine, ${ }^{7}$ Division of Pulmonary, Allergy and Critical Care Medicine, Department of Internal Medicine, Konkuk University School of Medicine, ${ }^{8}$ Division of Pulmonary, Allergy and Critical Care Medicine, Department of Internal Medicine, Seoul St Mary's Hospital,

College of Medicine, The Catholic University of Korea, Seoul, Republic of Korea

Correspondence: Young Kyoon Kim; Chin Kook Rhee

Division of Pulmonary, Allergy and Critical Care Medicine, Department of Internal Medicine, Seoul St Mary's Hospital, College of Medicine, The Catholic University of Korea, Seoul, Republic of Korea, 222, Banpo-daero Seocho-gu, Seoul 0659I, Republic of Korea Tel +82 222586059 ;

+82222586067

Fax +82 2599358

Email youngkim@catholic.ac.kr;

chinkook77@gmail.com
Introduction: A low body mass index (BMI) is associated with increased mortality and low health-related quality of life in patients with COPD. The Asia-Pacific classification of BMI has a lower cutoff for overweight and obese categories compared to the World Health Organization (WHO) classification. The present study assessed patients with COPD among different BMI categories according to two BMI classification systems: WHO and Asia-Pacific. Patients and methods: Patients with COPD aged 40 years or older from the Korean COPD Subtype Study cohort were selected for evaluation. We enrolled 1,462 patients. Medical history including age, sex, St George's Respiratory Questionnaire (SGRQ-C), the modified Medical Research Council (mMRC) dyspnea scale, and post-bronchodilator forced expiratory volume in 1 second $\left(\mathrm{FEV}_{1}\right)$ were evaluated. Patients were categorized into different BMI groups according to the two BMI classification systems.

Result: $\mathrm{FEV}_{1}$ and the diffusing capacity of the lung for carbon monoxide (DLCO) percentage revealed an inverse "U"-shaped pattern as the BMI groups changed from underweight to obese when WHO cutoffs were applied. When Asia-Pacific cutoffs were applied, FEV 1 and DLCO (\%) exhibited a linearly ascending relationship as the BMI increased, and the percentage of patients in the overweight and obese groups linearly decreased with increasing severity of the Global Initiative for Chronic Obstructive Lung Disease criteria. From the underweight to the overweight groups, SGRQ-C and mMRC had a decreasing relationship in both the WHO and Asia-Pacific classifications. The prevalence of comorbidities in the different BMI groups showed similar trends in both BMI classifications systems.

Conclusion: The present study demonstrated that patients with COPD who have a high BMI have better pulmonary function and health-related quality of life and reduced dyspnea symptoms. Furthermore, the Asia-Pacific BMI classification more appropriately reflects the correlation of obesity and disease manifestation in Asian COPD patients than the WHO classification.

Keywords: body mass index, COPD, comorbidity

\section{Introduction}

COPD is a slowly progressive disorder characterized by partially reversible chronic airway obstruction. ${ }^{1,2}$ Besides its lung manifestation, COPD has been considered to be a systemic disease in recent years due to its significant extrapulmonary findings. ${ }^{3}$ The body mass index (BMI), which can indirectly represent the degree of obesity, is one of the variables that affects the phenotypic expression of the disease, its course, and prognosis..$^{3-9}$ Use of the BMI is recommended by the National Heart Lung and Blood Institute (NHLBI) ${ }^{10}$ and it has been shown to contribute toward the expression of COPD phenotypes. ${ }^{11,12}$ BMI is included in the Body-Mass Index, Airflow Obstruction, 
Dyspnea, and Exercise (BODE) index, which predicts the prognosis of patients with COPD. ${ }^{3}$ A low BMI is associated with increased mortality in patients with $\mathrm{COPD}^{3,10,13}$ through its influences on pulmonary mechanics, ${ }^{14}$ diaphragmatic muscle weakness, ${ }^{15}$ decreased lung function, ${ }^{16}$ as well as systemic inflammation and its biomarkers. ${ }^{17,18}$ Furthermore, a low body weight is associated with low health-related quality of life. ${ }^{19-21}$

With the increasing prevalence of obesity in Asia, BMI as a disease predictor has increased in importance. However, there has been controversy when applying international criteria for obesity to an Asian population, and there have been attempts to reinterpret the BMI cutoffs for Asian and Pacific populations. $^{22,23}$ The World Health Organization (WHO) expert consultation identified further potential public health action points $\left(23.0,27.5,32.5\right.$, and $\left.37.5 \mathrm{~kg} / \mathrm{m}^{2}\right) .{ }^{24}$ In AsiaPacific countries including Korea, the agreed cutoff for inclusion in the overweight category is $23.0 \mathrm{~kg} / \mathrm{m}^{2} .{ }^{25}$ Asian populations have a higher risk of developing comorbidities such as cardiovascular disease and type 2 diabetes at BMIs lower than $25 \mathrm{~kg} / \mathrm{m}^{2}$, which is the WHO cutoff point for overweight and, in addition, association between BMI and body fat percentage is different from that for Europeans. ${ }^{24}$ The prevalence of metabolically obese but normal-weight patients in Korea is almost twice that found in the United States (US) population ${ }^{26}$ and, compared to the non-Asian population, their muscle mass is smaller.

Very few studies have evaluated the correlation between BMI and the disease severity of patients with COPD according to the degree of obesity in Asians. We hypothesized that patients with COPD in different BMI groups would exhibit different manifestations of COPD and proportions of comorbidities. In addition, applying two BMI classifications and comparing the related clinical variables can be clinically significant and, to our knowledge, no study comparing two BMI classification systems has been reported.

Our study compared the clinical characteristics, disease severity, and COPD-related comorbidities of Korean patients with COPD in different BMI categories based on both the WHO and Asia-Pacific BMI classifications.

\section{Patients and methods Study participants}

Patients registered in the Korean COPD Subtype Study (KOCOSS) were recruited from 48 tertiary referral hospitals in Korea and were required to visit the hospital to update their COPD status by self-administered questionnaires at least every 6 months. ${ }^{27}$ The inclusion criteria were as follows: age $\geq 40$ years and post-bronchodilator forced expiratory volume in 1 second $\left(\mathrm{FEV}_{1}\right)$ / forced vital capacity $(\mathrm{FVC})<0.7$. The medical history taken from patient questionnaires as well as measurements from their initial visit were used as baseline data. Age, sex, St George's Respiratory Questionnaire (SGRQ-C) response, and the modified Medical Research Council (mMRC) dyspnea scale score of patients were recorded. Post-bronchodilator $\mathrm{FEV}_{1}, \mathrm{FVC}$, and $\mathrm{FEV}_{1} /$ FVC were checked by pulmonary function tests. Six-minute walk tests (6MWT) were also performed at the time of enrollment.

\section{BMI and categorization}

According to the NHLBI, ${ }^{10}$ BMI is calculated as weight in kilograms divided by the square of the height in meters $\left(\mathrm{kg} / \mathrm{m}^{2}\right)$ and is categorized into four groups according to the Asian-Pacific cutoff points (Table 1): ${ }^{25}$ underweight $\left(<18.5 \mathrm{~kg} / \mathrm{m}^{2}\right)$, normal weight $\left(18.5-22.9 \mathrm{~kg} / \mathrm{m}^{2}\right)$, overweight $\left(23-24.9 \mathrm{~kg} / \mathrm{m}^{2}\right)$, and obese $\left(\geq 25 \mathrm{~kg} / \mathrm{m}^{2}\right)$. For comparison, BMI was also categorized into four groups according to the conventional WHO classification: ${ }^{10}$ underweight $\left(<18.5 \mathrm{~kg} / \mathrm{m}^{2}\right)$, normal weight $\left(18.5-24.9 \mathrm{~kg} / \mathrm{m}^{2}\right)$, overweight $\left(25-29.9 \mathrm{~kg} / \mathrm{m}^{2}\right)$, and obese $\left(\geq 30 \mathrm{~kg} / \mathrm{m}^{2}\right)$.

\section{Ethnic backgrounds}

Among Korean nationals, 96\% are of Korean origin and most immigrants have an Asian background (People's Republic of China, Vietnam, Japan, etc). ${ }^{28}$ All patients in this cohort were citizens of the Republic of Korea.

\section{Comorbidities}

At the time of enrollment to the cohort, patient comorbidities were checked. History of myocardial infarction, heart failure, peripheral vessel disease, diabetes mellitus, hypertension, osteoporosis, gastroesophageal reflux disease, dyslipidemia, thyroid disorder, inflammatory bowel disease, bronchiectasis, previously diagnosed COPD, measles, pertussis, pneumonia, asthma, allergic rhinitis, and atopic dermatitis were carefully evaluated.

Table I Obesity classification according to $\mathrm{WHO}$ and AsiaPacific guidelines

\begin{tabular}{lll}
\hline & WHO (BMI) & Asia-Pacific (BMI) \\
\hline Underweight & $<18.5$ & $<18.5$ \\
Normal & $18.5-24.9$ & $18.5-22.9$ \\
Overweight & $25-29.9$ & $23-24.9$ \\
Obese & $\geq 30$ & $\geq 25$ \\
\hline
\end{tabular}

Abbreviations: WHO, World Health Organization; BMI, body mass index. 


\section{Ethics statement}

For KOCOSS patients, written informed consent was obtained from all study participants. Ethics approval for the KOCOSS cohort was obtained from the ethics committee at each center. We also received approval from each center to use clinical records of their subjects for the study while maintaining patient confidentiality with regard to the data. The official name of each approving ethics committee is listed in the Supplementary materials.

\section{Statistical analysis}

Continuous variables are reported as mean \pm standard deviation. When comparing clinical parameters between BMI groups, an analysis of variance (ANOVA) test was performed for continuous variables, while the chi-squared test was performed for categorical variables. Pearson's coefficient comparison was used to determine linear associations between numerical variables. Statistical significance was established at a $P$-value $<0.05$. The Mantel-Haenszel chi-squared test was performed to determine the association between categorical variables.

\section{Results}

\section{Clinical characteristics}

Table 2 lists the baseline characteristics of the study participants. The study included 1,462 subjects, and the number of male patients was 1,396 (90.8\%). The mean patient age was $70.5 \pm 7.8$ years. The predicted mean post-bronchodilator $\mathrm{FEV}_{1}$ percentage was $55.6 \% \pm 18.3 \%$. The mean $\mathrm{FVC}$ was

Table 2 Baseline characteristics of COPD patients $(n=I, 462)$

\begin{tabular}{ll}
\hline Characteristics & Mean \pm SEM or no (\%) \\
\hline Male & $1,396(90.8 \%)$ \\
Age & $70.5 \pm 7.8$ \\
SGRQ-C & $34.6 \pm 19.0$ \\
mMRC & $1.5 \pm 0.9$ \\
Post-BD FVC (\%) & $80.5 \pm 17.5$ \\
Post-BD FEV,$(\%)$ & $55.6 \pm 18.3$ \\
GOLD I & $127(8.7 \%)$ \\
GOLD 2 & $754(51.9 \%)$ \\
GOLD 3 & $475(32.7 \%)$ \\
GOLD 4 & $98(6.7 \%)$ \\
Post-BD FEV $/$ FVC (\%) & $48.8 \pm 12.3$ \\
BMI $\left(\mathrm{kg} / \mathrm{m}^{2}\right)$ & $22.8 \pm 3.4$ \\
6MWT $(\mathrm{m})$ & $371.4 \pm 117.5$ \\
\hline
\end{tabular}

Abbreviations: SGRQ-C, St George's Respiratory Questionnaire; CAT, COPD assessment test; mMRC, modified Medical Research Council; BD, bronchodilator: GOLD, Global Initiative for Chronic Obstructive Lung Disease; FEV , forced expiratory volume per I second; FVC, forced vital capacity; BMI, body mass index; 6MWT, 6-minute walk test.
80.5 \pm 17.5 and $\mathrm{FEV}_{1} / \mathrm{FVC}$ was $48.8 \pm 12.3$. The mean BMI was $22.8 \pm 3.4 \mathrm{~kg} / \mathrm{m}^{2}$. The Global Initiative for Chronic Obstructive Lung Disease (GOLD) stage II was seen in the greatest proportion of this COPD cohort, with 758 (52.0\%) patients falling into this category. The mean SGRQ-C was $34.6 \pm 19.0$ and the mean COPD assessment test score was $15.8 \pm 7.8$. The mean mMRC score was $1.5 \pm 0.9$.

\section{Distribution of BMI}

Figures 1 and 2 present the distribution of BMI values among study subjects. The mean BMI value was 22.8 [95\% confidence interval (CI) 22.6-23.0] and the median value was 22.7. The lowest BMI value was 13.50 , whereas the highest was 35.99 (Figure 1). Figure 2 shows the distribution of BMI values among the entire study population.

\section{Correlation of major variables with different BMI categories}

The SGRQ-C was found to be in a linearly decreasing relationship with BMI (Pearson coefficient of correlation $\mathrm{r}=-0.14, P<0.01)$. However, the post-bronchodilator $\mathrm{FEV}_{1}$ was in a linearly increasing relationship with BMI ( $\mathrm{r}=0.21$, $P<0.01)$. The diffusing capacity of the lung for carbon monoxide (DLCO) percentage and DLCO/alveolar volume (VA) were also in a linearly increasing relationship with BMI (r=0.22, $P<0.01$ and $\mathrm{r}=0.41, P<0.01$, respectively; Figure 3).

Furthermore, we evaluated differences in the values of major variables when the BMI groups changed (Table 3). Changes in variables were also evaluated according to each classification system (WHO and Asia-Pacific). No significant change in the mean age was observed in either

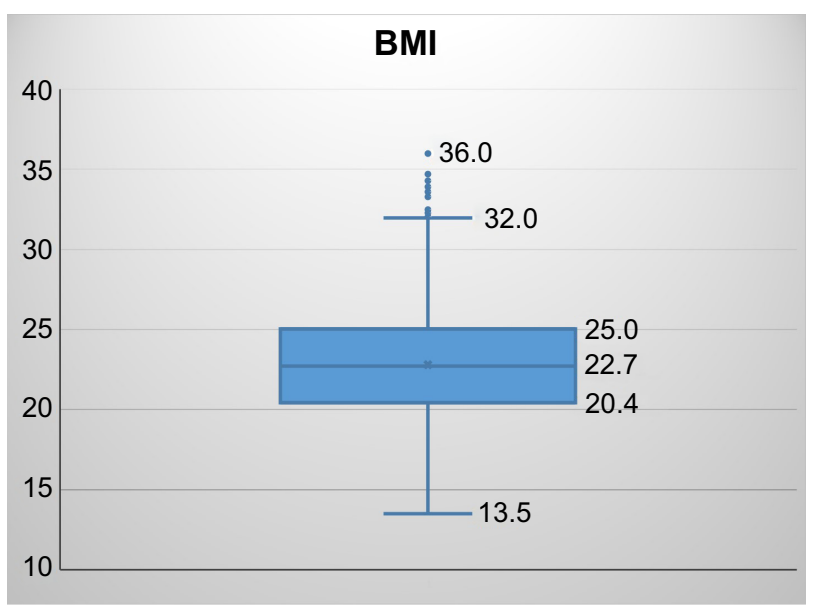

Figure I Distribution of the body mass index of the study patients. Abbreviation: BMI, body mass index. 


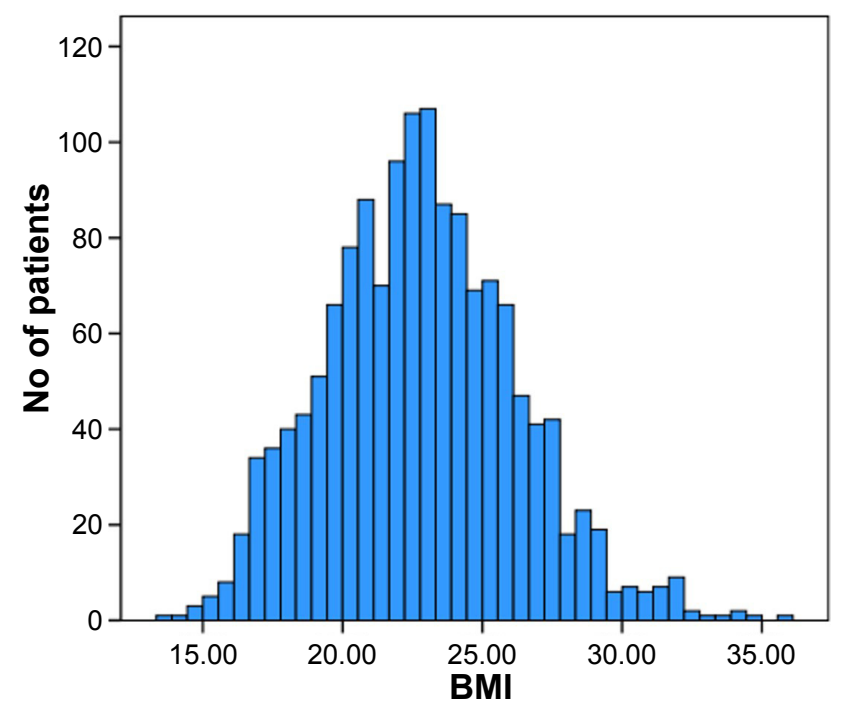

Figure 2 Bar graphs showing the distribution of the body mass index of the study patients.

Abbreviations: BMI, body mass index; No, number.

classification. A comparison of the normal weight group to the overweight group revealed that the proportion of male patients decreased gradually. Between the underweight and normal weight groups, SGRQ-C and mMRC scores were in

a decreasing relationship in both the WHO and Asia-Pacific classifications. However, the two variables increased from the overweight to the obese group.

When the WHO cutoffs were applied, an inverse "U"-shaped pattern was observed for FEV ${ }_{1}$. When the AsiaPacific cutoffs were applied, $\mathrm{FEV}_{1}$ was in a linearly ascending relationship, whereas DLCO (\%) was in a linearly increasing relationship with BMI when the Asia-Pacific cutoffs were applied. However, DLCO (\%) had an inverse "U"-shaped pattern when the WHO cutoffs were applied (Table 3).

\section{FEV $(\%)$ and $\mathrm{BMI}$ categories}

We compared the mean BMI of the groups of patients classified according to the GOLD criteria (Figure 4) and found that mean BMI decreases as the severity of airway obstruction increases. Mean BMI was $23.6 \mathrm{~kg} / \mathrm{m}^{2}$ in the GOLD 1 group and $21.2 \mathrm{~kg} / \mathrm{m}^{2}$ in the GOLD 4 group. Figure 5 shows the proportion of each BMI group. Figure 5A shows the proportion of each BMI group according to the WHO cutoffs, and Figure 5B shows proportions according to the Asia-Pacific cutoffs. When WHO cutoffs were applied,
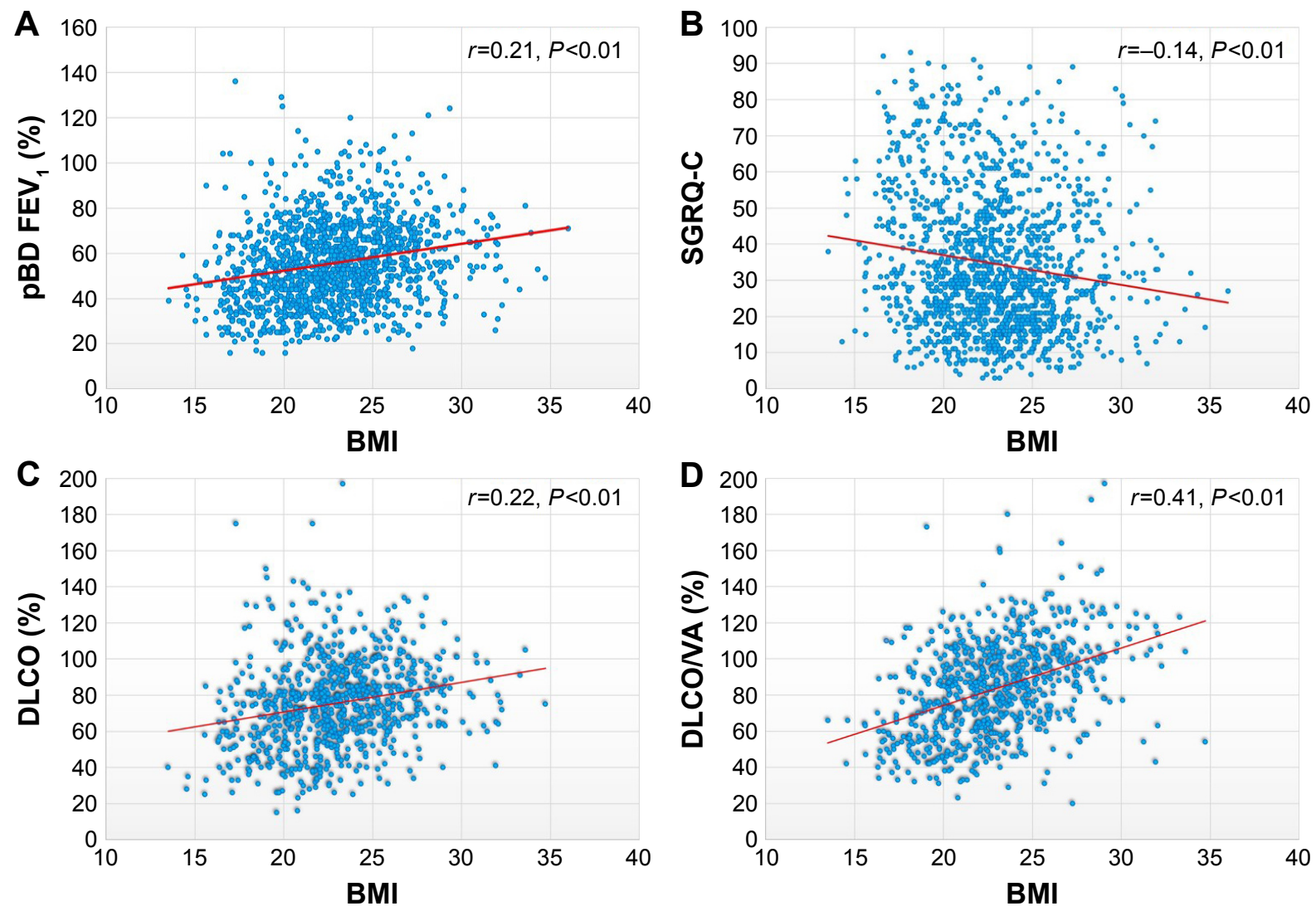

Figure 3 Correlation of the body mass index to (A) PBD FEV, (\%), (B) SGRQ-C, (C) DLCO (\%), and (D) DLCO/VA (\%). Note: Statistical significance was established at a $P$-value $<0.05$.

Abbreviations: PBD, post-bronchodilator; FEV , forced expiratory volume in I second; SGRQ-C, St George's Respiratory Questionnaire; DLCO, diffusing capacity of the lung for carbon monoxide; VA, alveolar volume; BMI, body mass index. 


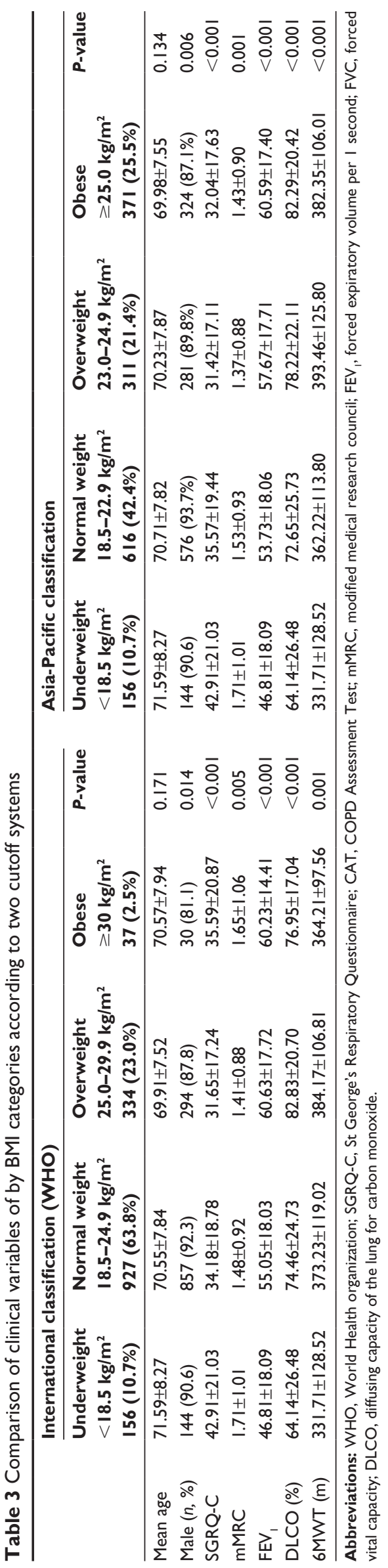

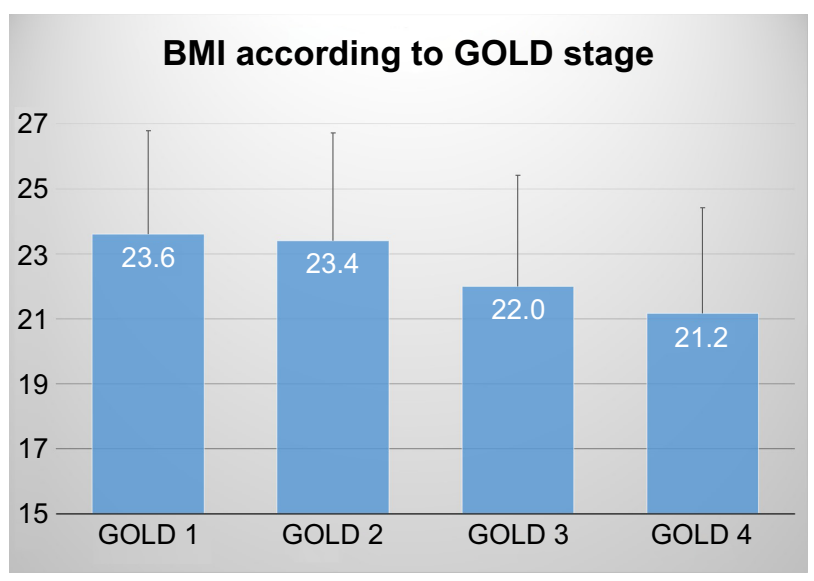

Figure 4 Body mass index according to GOLD stage.

Abbreviations: BMI, body mass index; GOLD, Global Initiative for Chronic Obstructive Lung Disease.

$2.4 \%$ of the patients fell into the obese category, while $25.5 \%$ of the patients were found to be obese according to the Asia-Pacific cutoffs.

Table 4 shows the proportion of each BMI group according to the GOLD criteria. As the severity of the GOLD criteria increases, proportions of the different BMI categories by both WHO and Asia-Pacific cutoffs change with statistical significance $(P$-value $<0.001)$. However, when WHO cutoffs were applied, the percentage of the obese group decreased after an initial increase. Conversely, when the Asia-Pacific cutoffs were applied, the percentage in the obese group linearly decreased as the GOLD criteria increased in severity. The percentage in the underweight patient group increased from $5.5 \%$ to $21.4 \%$ as the GOLD criteria changed from 1 to 4 for both BMI classifications.

\section{Comorbidities}

Comorbidities were observed in different percentages in different BMI categories. Figure 6A presents the comorbidities of patients in different BMI groups classified according to the WHO cutoffs, while Figure 6B presents those in BMI groups according to the Asia-Pacific cutoffs. Both graphs show that the percentage of patients with hypertension, diabetes, and hyperlipidemia increased as the groups became more obese. The percentage of patients with congestive heart failure, myocardial infarction, and peripheral vascular disease was also highest in the obese groups. Osteoporosis had the highest proportion of patients in the obese group when the WHO classification was applied and also had the highest proportion of patients in the underweight group when the Asia-Pacific classification was applied (Figure 6). 


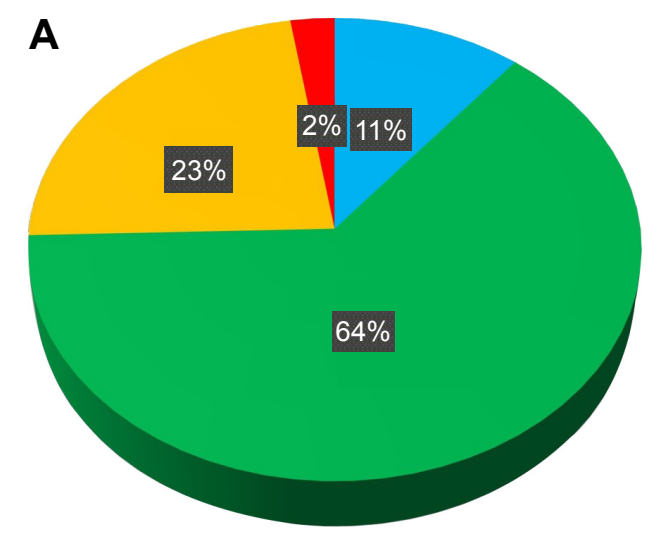

UnderWt $\square$ Normal OverWt $\square$ Obesity

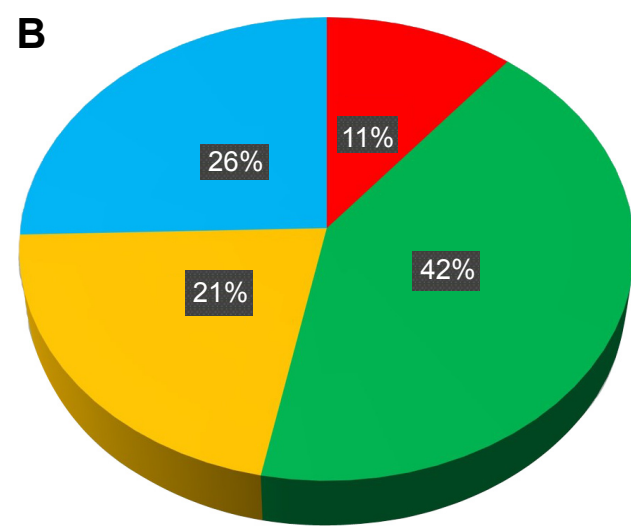

UnderWt Normal OverWt Obesity

Figure 5 Pie charts showing the proportion of patients in each body mass index group according to (A) the World Health Organization (WHO) classification and (B) the Asia-Pacific classification.

Note: Decimals were rounded to the nearest whole number.

Abbreviation: Wt, weight.

\section{Discussion}

The present COPD cohort study evaluated COPD manifestation and comorbidity in different BMI categories. First, $\mathrm{FEV}_{1}$ worsened as the BMI groups changed from obese to underweight. Second, the quality of life and dyspnea score improved as the BMI groups changed from underweight to overweight. Third, comorbidities were observed in different proportions according to the BMI group. Two BMI classifications were used to assess the clinical correlation between clinical parameters and BMI, and several differences were observed.

These results reveal that a low BMI is associated with worse health-related quality of life in patients with COPD, and this result is consistent with those of previous studies. ${ }^{19-21,29}$ The study by Divo et al shows that the dyspnea score and SGRQ-C showed a "U" shape as the BMI category changed from underweight to obese. ${ }^{30}$ In the present study, SGRQ-C and $\mathrm{mMRC}$ scores were lowest for the overweight group and increased in the obese group, similar to the result from a previous study. ${ }^{30}$ We speculate that SGRQ-C and mMRC were worse for obese patients compared to overweight patients, due to the influence of obesity on the activities of patients with COPD. An increase in fat mass is likely to be associated with functional limitation. ${ }^{31}$ Metabolic comorbidity associated with obesity may also be a contributing factor to the relative worsening of quality of life of these patients.

Post-bronchodilator $\mathrm{FEV}_{1}$ decreased as the patients' BMI decreased. Previous studies have reported that BMI is correlated with the severity of emphysema, with low-BMI COPD patients more likely to have this condition; ${ }^{30,32,33}$ such findings can provide an explanation for the linear decrease of $\mathrm{FEV}_{1}$ in the low-BMI group. In addition to previously reported results, the DLCO percentage gradually increased as patients were classified into groups of increasing obesity. Such a correlation between DLCO and obesity is controversial. Some studies have reported increased DLCO in more obese patients, ${ }^{30,34-36}$ while other studies have observed unchanged or reduced DLCO in obese patients. ${ }^{37-39}$ Nevertheless, a linear decrease of DLCO in lower BMI groups should be interpreted as a correlation between emphysema and low body mass, as previous studies showing a correlation between DLCO and emphysema suggest. ${ }^{40,41}$ Clinical relationships of $\mathrm{FEV}_{1}$ and DLCO to BMI also support the previously mentioned "obesity paradox" in which patients with COPD with higher BMI have better prognosis compared to low BMI groups. ${ }^{42,43}$

In this study, the WHO and Asia-Pacific BMI classifications were simultaneously applied to assess patients with COPD, and major clinical variables were evaluated for each classification system. To our knowledge, no study comparing two BMI classifications in Asian patients with COPD has previously been reported. Both BMI classification systems revealed similar changes in major variables as the patients became more obese (Table 3). However, when the AsiaPacific cutoffs were applied, changes in the SGRQ-C and mMRC scores were more constant as the patients fell into the more obese groups. The change in $\mathrm{FEV}_{1} \%$ was more gradual compared to when the WHO cutoffs were applied.

Furthermore, when the WHO classification was applied, the proportion of obese patients was too low (2.5\%) to allow a 


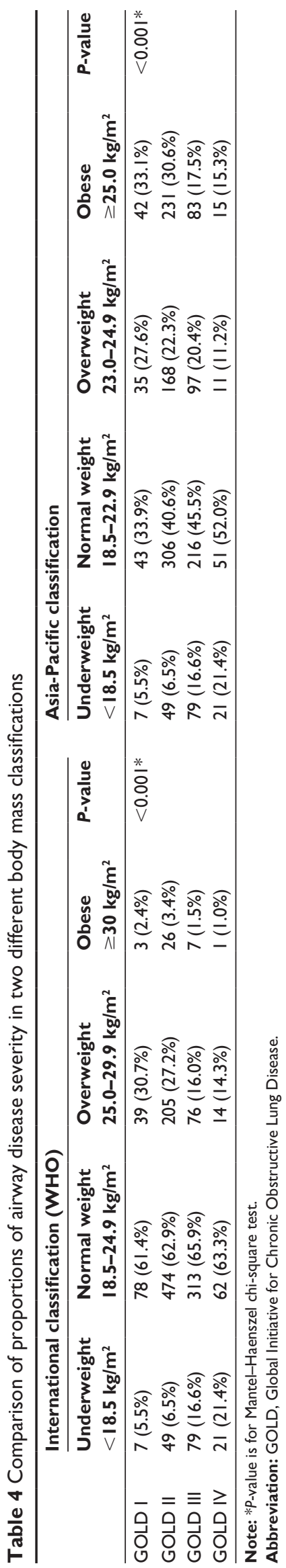

comparison with less obese patients. The proportions of obese patients were $29.6 \%$ according to the studies on the distribution of BMI among patients with COPD in both Spain $^{44}$ as well as the Middle East and North Africa. ${ }^{45}$ The study by Rodríguez et al showed that the proportion of the obese was $43 \%$ among the selected patients with COPD. ${ }^{46}$ In addition, when evaluating the clinical parameters associated with BMI, such as health-related quality of life, dyspnea score, and respiratory functions, Asia-Pacific classifications can be more appropriate than WHO classifications in Asian patients with COPD.

We assume that the Asia-Pacific BMI classification is more appropriate for Asian patients for the following reasons. A previous study suggested that weight loss in patients with COPD is due to a loss of skeletal muscle volume; on the other hand, a change in fat mass is not a significant contributor. ${ }^{47}$ Furthermore, the fat-free mass index (FFMI) is reported to be more significant than fat mass in the assessment of quality of life and respiratory function of patients with COPD. ${ }^{48,49}$ According to the evaluation of Korea National Health and Nutrition Examination Survey (KNHANES), mean BMI and appendicular skeletal muscle (ASM) of Koreans were $24.0 \pm 0.0 \mathrm{~kg} / \mathrm{m}^{2}$ and $22.6 \pm 0.1 \mathrm{~kg}$ in men and $23.2 \pm 0.1 \mathrm{~kg} / \mathrm{m}^{2}$ and $14.5 \pm 0.0 \mathrm{~kg}$ in women, respectively. ${ }^{50,51}$ In contrast, average BMI and ASM from the US population sample from the National Health and Nutrition Examination Survey (NHANES) were $27.9 \pm 0.10 \mathrm{~kg} / \mathrm{m}^{2}$ and $26.5 \pm 0.1 \mathrm{~kg}$ in men and $28.2 \pm 0.14$ in women and $17.8 \pm 0.1 \mathrm{~kg}$, respectively. ${ }^{52,53}$ Because the Asia-Pacific grading of obesity is based on a consensus that the skeletal and muscle mass of patients in the Asia-Pacific region is lower than that in the West, ${ }^{25}$ we might, therefore, expect a better correlation between BMI according to the Asia-Pacific guidelines than with the WHO grading in Asian patients with COPD.

Metabolic and cardiac problems were more frequent in the obese groups, and such a finding is consistent with the previous study on patients with $\mathrm{COPD}^{30}$ and distribution of comorbidities among the general population. ${ }^{54,55}$ The prevalence of metabolic disease and cardiovascular disease were much higher when the WHO classification was applied as compared to when the Asia-Pacific classification was applied. The proportion of patients with major comorbidities may differ according to the two different BMI classifications, but the patterns of increase or decrease according to the BMI of the patients with COPD were similar. Moreover, due to the extremely small number of patients falling into the obese category when the WHO cutoffs were applied, some comorbidities such as osteoporosis had an inappropriately high prevalence. 

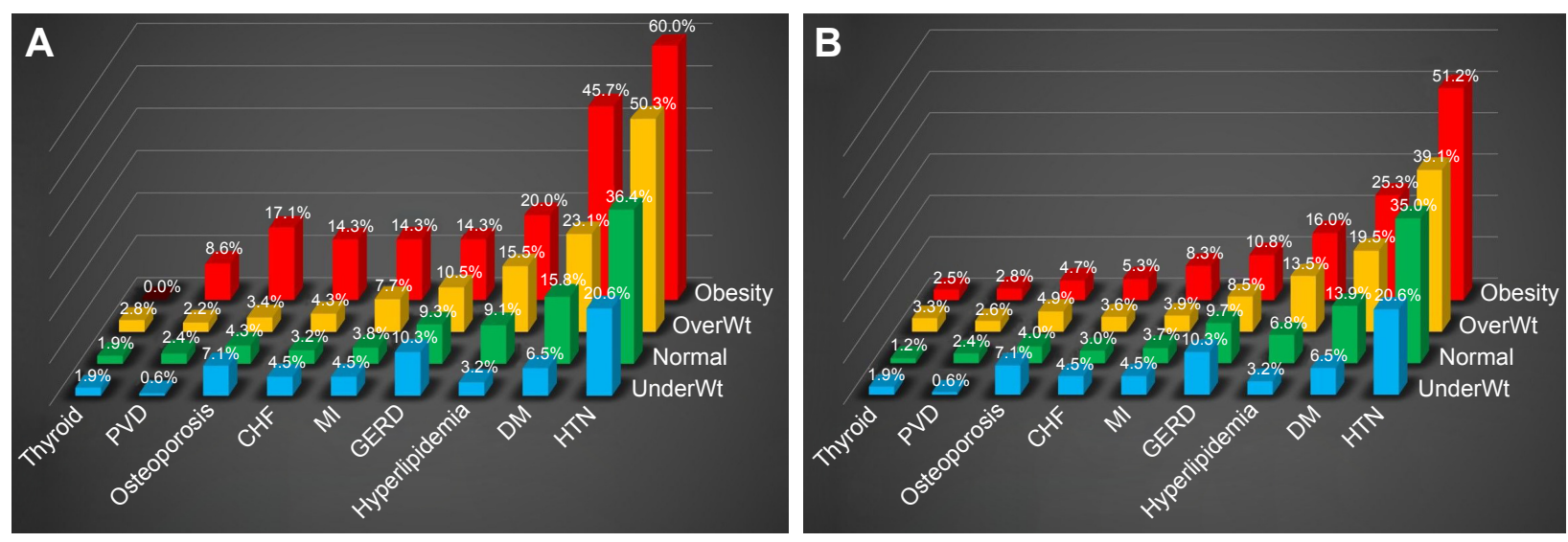

Figure 6 Prevalence of comorbidities in different body mass index groups according to (A) the World Health Organization (WHO) classification and (B) the Asia-Pacific classification.

Abbreviations: PVD, peripheral vascular disease; CHF, congestive heart failure; MI, myocardial infarction; GERD, gastroesophageal reflux disease; DM, diabetes mellitus; HTN, hypertension; Wt, weight.

It is widely known that Asian and Western populations differ in mean body mass. However, few studies have compared BMI between Western and Asian patients with COPD. No statistical analysis was conducted for comparison with the other cohorts due to lack of raw data; however, the present study indirectly compared mean BMI of Korean patients with COPD to both Japanese and Western patients with COPD. Interestingly, compared with other major COPD cohorts, the mean BMI of the KOCOSS cohort was much lower than that in the Evaluation of COPD Longitudinally to Identify Predictive Surrogate Endpoints (ECLIPSE; $\left.27 \pm 6 \mathrm{~kg} / \mathrm{m}^{2}\right),{ }^{.56}$ such a finding can be explained by the difference in body mass between Western and Asian populations. As expected, the

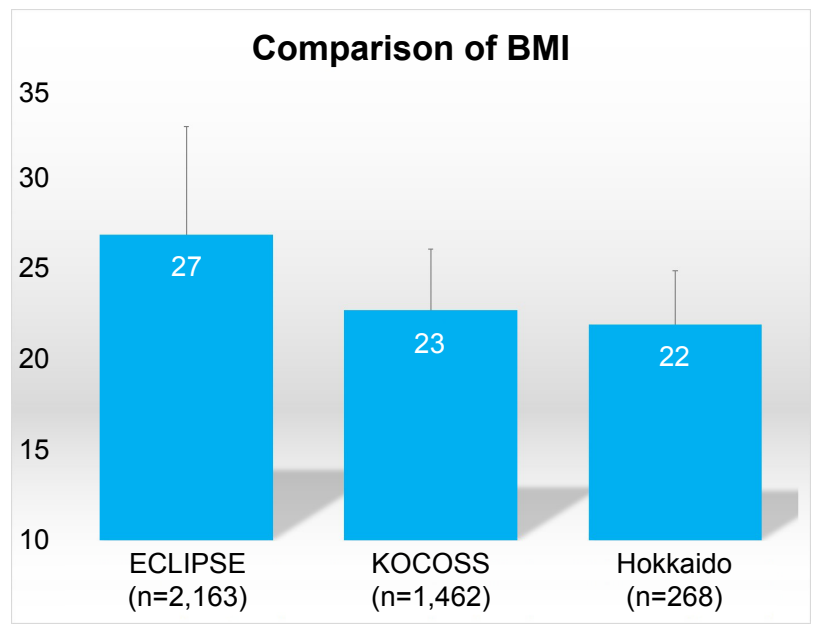

Figure 7 Comparison of the mean body mass index of the study patients with the ECLIPSE and Hokkaido cohorts.

Note: Decimals were rounded to the nearest whole number.

Abbreviations: BMI, body mass index; ECLIPSE, Evaluation of COPD Longitudinally to Identify Predictive Surrogate Endpoints; KOCOSS, Korean COPD Subtype Study.
Hokkaido cohort's mean BMI $\left(22 \pm 3 \mathrm{~kg} / \mathrm{m}^{2}\right)^{57,58}$ was similar to that for the KOCOSS patients $\left(23 \pm 3 \mathrm{~kg} / \mathrm{m}^{2}\right.$; Figure 7$)$.

Our study has a few limitations. First, due to the relatively short duration of the observation period of our recently constructed cohort, the mortality of the study patients could not be evaluated. Second, the body composition data, comprising fat and skeletal muscle mass and quadriceps muscle strength, of patients were not measured. Due to lack of body composition data, evaluation of the association of clinical parameters such as lung function and symptom score to FFMM was limited. We planned to include body composition data for the future study. However, we performed the 6 MWT to evaluate the functional capacity of these patients.

\section{Conclusion}

The present study revealed that patients with COPD with a high BMI had better pulmonary function and health-related quality of life and fewer dyspnea symptoms. Furthermore, the results suggest that the Asia-Pacific BMI classification is more appropriate in reflecting the correlation between obesity and the manifestation of COPD in Asian patients compared to that with the WHO classification system. Further studies regarding the clinical significance of BMI classification in Asian patients with COPD are needed.

\section{Acknowledgment}

The English in this document has been checked by at least two professional editors, both native speakers of English.

\section{Disclosure}

The authors report no conflicts of interest in this work. 


\section{References}

1. Pauwels RA, Buist AS, Calverley PM, Jenkins CR, Hurd SS; GOLD Scientific Committee. Global strategy for the diagnosis, management, and prevention of chronic obstructive pulmonary disease. NHLBI/ WHO Global Initiative for Chronic Obstructive Lung Disease (GOLD) Workshop summary. Am J Respir Crit Care Med. 2001;163(5): 1256-1276.

2. Celli BR, MacNee W; ATS/ERS Task Force. Standards for the diagnosis and treatment of patients with COPD: a summary of the ATS/ERS position paper. Eur Respir J. 2004;23(6):932-946.

3. Celli BR, Cote CG, Marin JM, et al. The body-mass index, airflow obstruction, dyspnea, and exercise capacity index in chronic obstructive pulmonary disease. N Engl J Med. 2004;350(10):1005-1012.

4. Casanova C, Aguirre-Jaíme A, de Torres JP, et al. Longitudinal assessment in COPD patients: multidimensional variability and outcomes. Eur Respir J. 2014;43(3):745-753.

5. Marin JM, Alfageme I, Almagro P, et al. Multicomponent indices to predict survival in COPD: the COCOMICS study. Eur Respir J. 2013; 42(2):323-332.

6. Vestbo J, Hurd SS, Agustí AG, et al. Global strategy for the diagnosis, management, and prevention of chronic obstructive pulmonary disease: GOLD executive summary. Am J Respir Crit Care Med. 2013;187(4): 347-365.

7. Pischon T, Boeing H, Hoffmann K, et al. General and abdominal adiposity and risk of death in Europe. $N$ Engl J Med. 2008;359(20): 2105-2120.

8. Castaldi PJ, Dy J, Ross J, et al. Cluster analysis in the COPD Gene study identifies subtypes of smokers with distinct patterns of airway disease and emphysema. Thorax. 2014;69(5):415-422.

9. Rennard SI, Locantore N, Delafont B, et al. Identification of five chronic obstructive pulmonary disease subgroups with different prognoses in the ECLIPSE cohort using cluster analysis. Ann Am Thorac Soc. 2015; 12(3):303-312.

10. Executive summary of the clinical guidelines on the identification, evaluation, and treatment of overweight and obesity in adults. Arch Intern Med. 1998;158(17):1855-1867.

11. Garcia-Aymerich J, Gómez FP, Benet M; PAC-COPD Study Group. Identification and prospective validation of clinically relevant chronic obstructive pulmonary disease (COPD) subtypes. Thorax. 2011;66(5):430-437.

12. Burgel PR, Paillasseur JL, Caillaud D; Initiatives BPCO Scientific Committee. Clinical COPD phenotypes: a novel approach using principal component and cluster analyses. Eur Respir J. 2010;36(3): 531-539.

13. Cao C, Wang R, Wang J, Bunjhoo H, Xu Y, Xiong W. Body mass index and mortality in chronic obstructive pulmonary disease: a meta-analysis. PLoS One. 2012;7(8):e43892.

14. Franssen FM, O’Donnell DE, Goossens GH, Blaak EE, Schols AM. Obesity and the lung: 5. Obesity and COPD. Thorax. 2008;63(12): 1110-1117.

15. Vestbo J, Prescott E, Almdal T, et al. Body mass, fat-free body mass, and prognosis in patients with chronic obstructive pulmonary disease from a random population sample: findings from the Copenhagen City Heart Study. Am J Respir Crit Care Med. 2006;173(1):79-83.

16. Coxson HO, Chan IH, Mayo JR, Hlynsky J, Nakano Y, Birmingham CL. Early emphysema in patients with anorexia nervosa. Am J Respir Crit Care Med. 2004;170(7):748-752.

17. Agusti A, Edwards LD, Rennard SI; Evaluation of COPD Longitudinally to Identify Predictive Surrogate Endpoints (ECLIPSE) Investigators Persistent systemic inflammation is associated with poor clinical outcomes in COPD: a novel phenotype. PLoS One. 2012;7(5):e37483.

18. Tomoda K, Yoshikawa M, Itoh T, et al. Elevated circulating plasma adiponectin in underweight patients with COPD. Chest. 2007;132(1): 135-140.

19. Hesselink AE, van der Windt DA, Penninx BW, et al. What predicts change in pulmonary function and quality of life in asthma or COPD? J Asthma. 2006;43(7):513-519.
20. Shoup R, Dalsky G, Warner S, et al. Body composition and healthrelated quality of life in patients with obstructive airways disease. Eur Respir J. 1997;10(7):1576-1580.

21. Katsura H, Yamada K, Kida K. Both generic and disease specific healthrelated quality of life are deteriorated in patients with underweight COPD. Respir Med. 2005;99(5):624-630.

22. WHO/IASO/IOTF. The Asia-Pacific perspective: redefining obesity and its treatment. Health Communications Australia: Melbourne. 2000.

23. James WP, Chunming C, Inoue S. Appropriate Asian body mass indices? Obes Rev. 2002;3(3):139.

24. WHO Expert Consultation. Appropriate body-mass index for Asian populations and its implications for policy and intervention strategies. Lancet. 2004;363(9403):157-163.

25. Pan WH, Yeh WT. How to define obesity? Evidence-based multiple action points for public awareness, screening, and treatment: an extension of Asian-Pacific recommendations. Asia Pac J Clin Nutr. 2008; 17(3):370-374.

26. Lee K. Metabolically obese but normal weight (MONW) and metabolically healthy but obese (MHO) phenotypes in Koreans: characteristics and health behaviors. Asia Pac J Clin Nutr. 2009;18(2):280-284.

27. Lee JY, Chon GR, Rhee CK, et al. Characteristics of patients with chronic obstructive pulmonary disease at the first visit to a pulmonary medical center in Korea: The KOrea COpd Subgroup Study Team Cohort. J Korean Med Sci. 2016;31(4):553-560.

28. Kostat.go.kr. Daejeon: Statistics Korea [updated 2016 Aug 04; cited 2017 Jun 12]. Available from: http://kostat.go.kr/portal/korea/index. action/. Accessed Jun 12, 2017

29. Tsiligianni I, Kocks J, Tzanakis N, Siafakas N, van der Molen T. Factors that influence disease-specific quality of life or health status in patients with COPD: a review and meta-analysis of Pearson correlations. Prim Care Respir J. 2011;20(3):257-268.

30. Divo MJ, Cabrera C, Casanova C, et al. Comorbidity distribution, clinical expression and survival in COPD patients with different body mass index. J COPD F. 2014;1(2):229-238.

31. Eisner MD, Blanc PD, Sidney S, et al. Body composition and functional limitation in COPD. Respir Res. 2007;8:7.

32. Renvall MJ, Friedman P, Ramsdell JW. Predictors of body mass index in patients with moderate to severe emphysema. COPD. 2009; 6(6):432-436.

33. Ogawa E, Nakano Y, Ohara T, et al. Body mass index in male patients with COPD: correlation with low attenuation areas on CT. Thorax. 2009;64(1):20-25.

34. Collard P, Wilputte JY, Aubert G, Rodenstein DO, Frans A. The single-breath diffusing capacity for carbon monoxide in obstructive sleep apnea and obesity. Chest. 1996;110(5):1189-1193.

35. Saydain G, Beck KC, Decker PA, Cowl CT, Scanlon PD. Clinical significance of elevated diffusing capacity. Chest. 2004;125(2): 446-452.

36. Ray CS, Sue DY, Bray G, Hansen JE, Wasserman K. Effects of obesity on respiratory function. Am Rev Respir Dis. 1983;128(3):501-506.

37. Biring MS, Lewis MI, Liu JT, Mohsenifar Z. Pulmonary physiologic changes of morbid obesity. Am J Med Sci. 1999;318(5):293-297.

38. Hakala K, Stenius-Aarniala B, Sovijärvi A. Effects of weight loss on peak flow variability, airways obstruction, and lung volumes in obese patients with asthma. Chest. 2000;118(5):1315-1321.

39. Ravipati G, Aronow WS, Sidana J, et al. Association of reduced carbon monoxide diffusing capacity with moderate or severe left ventricular diastolic dysfunction in obese persons. Chest. 2005;128(3): 1620-1622.

40. Holme J, Stockley RA. Radiologic and clinical features of COPD patients with discordant pulmonary physiology: lessons from alpha1antitrypsin deficiency. Chest. 2007;132(3):909-915.

41. van der Lee I, Gietema HA, Zanen P, et al. Nitric oxide diffusing capacity versus spirometry in the early diagnosis of emphysema in smokers Respir Med. 2009;103(12):1892-1897.

42. Jee SH, Sull JW, Park J, et al. Body-mass index and mortality in Korean men and women. $N$ Engl J Med. 2006;355(8):779-787. 
43. Landbo C, Prescott E, Lange P, Vestbo J, Almdal TP. Prognostic value of nutritional status in chronic obstructive pulmonary disease. Am J Respir Crit Care Med. 1999;160(6):1856-1861.

44. García-Rio F, Soriano JB, Miravitlles M, et al. Impact of obesity on the clinical profile of a population-based sample with chronic obstructive pulmonary disease. PLoS One. 2014;9(8):e105220.

45. Koniski ML, Salhi H, Lahlou A, Rashid N, El Hasnaoui A. Distribution of body mass index among subjects with COPD in the Middle East and North Africa region: data from the BREATHE study. Int J Chron Obstruct Pulmon Dis. 2015;10:1685-1694.

46. Rodríguez DA, Garcia-Aymerich J, Valera JL, et al. Determinants of exercise capacity in obese and non-obese COPD patients. Respir Med. 2014;108(5):745-751.

47. Ischaki E, Papatheodorou G, Gaki E, Papa I, Koulouris N, Loukides S. Body mass and fat-free mass indices in COPD: relation with variables expressing disease severity. Chest. 2007;132(1):164-169.

48. Planas M, Alvarez J, Garcia-Peris PA, et al. Nutritional support and quality of life in stable chronic obstructive pulmonary disease (COPD) patients. Clin Nutr. 2005;24(3):433-441.

49. McDonald VM, Gibson PG, Scott HA, et al. Should we treat obesity in COPD? The effects of diet and resistance exercise training. Respirology. 2016;21(5):875-882.

50. Kim SG, Ko K, Hwang IC, et al. Relationship between indices of obesity obtained by anthropometry and dual-energy X-ray absorptiometry: The Fourth and Fifth Korea National Health and Nutrition Examination Survey (KNHANES IV and V, 2008-2011). Obes Res Clin Pract. 2015; 9(5):487-498.
51. Kim Y, Han BD, Han K, et al. Optimal cutoffs for low skeletal muscle mass related to cardiovascular risk in adults: The Korea National Health and Nutrition Examination Survey 2009-2010. Endocrine. 2015;50(2): 424-433.

52. Flegal KM, Shepherd JA, Looker AC, et al. Comparisons of percentage body fat, body mass index, waist circumference, and waist-stature ratio in adults. Am J Clin Nutr. 2009;89(2):500-508.

53. Prado CM, Siervo M, Mire E, et al. A population-based approach to define body-composition phenotypes. Am J Clin Nutr. 2014;99(6): 1369-1377.

54. Aronson D, Bartha $\mathrm{P}$, Zinder O, et al. Obesity is the major determinant of elevated C-reactive protein in subjects with the metabolic syndrome. Int J Obes Relat Metab Disord. 2004;28(5):674-679.

55. Florez H, Castillo-Florez S, Mendez A, et al. C-reactive protein is elevated in obese patients with the metabolic syndrome. Diabetes Res Clin Pract. 2006;71(1):92-100.

56. Vestbo J, Edwards LD, Scanlon PD, et al; ECLIPSE Investigators. Changes in forced expiratory volume in 1 second over time in COPD. N Engl J Med. 2011;365(13):1184-1192.

57. Suzuki M, Makita H, Konno S, et al; Hokkaido COPD Cohort Study Investigators. Asthma-like features and clinical course of chronic obstructive pulmonary disease. An analysis from the Hokkaido COPD cohort study. Am J Respir Crit Care Med. 2016;194(11):1358-1365.

58. Hizawa N, Makita H, Nasuhara Y, et al; Hokkaido COPD Cohort Study Group. Functional single nucleotide polymorphisms of the CCL5 gene and nonemphysematous phenotype in COPD patients. Eur Respir J. 2008;32(2):372-378. 


\section{Supplementary materials}

The names of ethics committees are as follows: Gacheon University Gil Medical Center, Hallym University Kangnam Sacred Heart Hospital, Gangnam Severance Hospital, Kyung Hee University Hospital at Gangdong, Hallym University Kangdong Sacred Heart Hospital, Kangbuk Samsung Hospital, Kangwon National University Hospital, Konkuk University Hospital, Konkuk University Chungju Hospital, Kyungpook National University Hospital, Gyeongsang National University Hospital, Korea University Guro Hospital, Korea University Anam Hospital, Seoul Eulji Hospital, Dongguk University Gyeongju Hospital, Dongguk University Ilsan Hospital, Keimyung University Dongsan Medical Center, Dong-A University Hospital, Hallym University Dongtan Sacred Heart Hospital, Pusan National University Hospital, Inje University Busan Paik Hospital, The Catholic University of Korea Bucheon St Mary's Hospital, Soonchunhyang University Hospital Bucheon, Seoul National University Bundang Hospital, Bundang CHA Hospital, Seoul Metropolitan Government Seoul National University Bora-mae Medical Center, Samsung Medical
Center, Soonchunhyang University Hospital Seoul, The Catholic University of Korea Seoul St Mary's Hospital, The Catholic University of Korea St Paul's Hospital, The Catholic University of Korea St Vincent's Hospital, Severance Hospital, Asan Medical Center, Ajou University Hospital, The Catholic University of Korea Yeouido St Mary's Hospital, The Catholic University of Korea Uijeongbu St Mary's Hospital, Yeungnam University Medical Center, Ulsan University Hospital, Wonkwang University Sanbon Hospital, Wonju Severance Christian Hospital, Ewha Womans University Mokding Hospital, Incheon St Mary's Hospital, Inha University Hospital, Chonnam National University Hospital, Chonbuk National University Hospital, Jeju National University Hospital, Soonchunhyang University Hospital Cheonan, Hallym University Chuncheon Sacred Heart Hospital, Hallym University Sacred Heart Hospital, and Hanyang University Guri Hospital.

We also received approval from each center to use their subjects' clinical records for the study while maintaining the confidentiality of the data.
International Journal of COPD

\section{Publish your work in this journal}

The International Journal of COPD is an international, peer-reviewed journal of therapeutics and pharmacology focusing on concise rapid reporting of clinical studies and reviews in COPD. Special focus is given to the pathophysiological processes underlying the disease, intervention programs, patient focused education, and self management protocols

\section{Dovepress}

This journal is indexed on PubMed Central, MedLine and CAS. The manuscript management system is completely online and includes a very quick and fair peer-review system, which is all easy to use. Visit http://www.dovepress.com/testimonials.php to read real quotes from published authors. 